\title{
Monitoring airborne dust in an Italian basalt quarry: comparison between sampling methods
}

\author{
G. Alfaro Degan, D. Lippiello \& M. Pinzari \\ Dipartimento di Ingegneria Meccanica e Industriale, \\ Università degli studi Roma Tre, Italy
}

\begin{abstract}
A field study in a dark grey basalt quarry nearby Rome is presented. $\mathrm{PM}_{10}$ airborne concentration due to typical quarry operations was recorded during a period of two months. The aim of the work is testing the suitability of the laser light scattering method in measuring airborne dust concentration in such typical environmental conditions like those from quarrying operations. To the scope, two sampling campaigns were developed according with two different methods: from one side a traditional gravimetric method (NIOSH 0600) based on an air sampling pump connected with PVC filters through a $37 \mathrm{~mm}$ aluminum cyclone was used to assess $\mathrm{PM}_{10}$ concentration. On the other hand, a light scatter technology developed with a real time dust monitor was applied. This method, which is based on a photo detector that measures laser light scattered by particles in the sampled stream, allows us to assess airborne dust concentration through a specific calibration generally carried out by comparing the time weighed average photometer readings with field measures of a known dust test (A1 Arizona Road Dust in this case). The step of assessing airborne dust concentration from a sampled particle number is a critical passage, as concentration itself is strictly connected to the physical and chemical characteristics of the sampled aerosol, such as particle size distribution, density and refractive index that obviously vary from pollutant to pollutant. So after a preliminary comparison of the sampled sets of values, some further analysis was developed in order to test the accuracy of the sampled values and the correlation factor was assessed. The $\mathrm{R}^{2}$ value $(0.706)$ showed a fairly good correlation between the two methods suggesting we consider the optical method suitable to survey $\mathrm{PM}_{10}$ in the specific case. So basalt airborne dust was taken into account and a field calibration was developed. The results showed a fulfilling improvement of correlation factor
\end{abstract}


(0.794) and a reduction of the bias. The study suggests, though further analysis is necessary, that in basalt quarries or similar activities (for example, brick factories) suffering from elevated levels of airborne dust concentration, the optical method may represent a suitable tool in monitoring $\mathrm{PM}_{10}$ concentration if integrated with gravimetric samples, aimed to provide a specific calibration for the target environment.

Keywords: $P M_{10}$, respirable dust, real time dust monitor, gravimetric sampler, calibration.

\section{Introduction}

Airborne dust, as well known, can be considered one of the most critical effects of quarrying activities on surrounding receptors. Total Suspended Particulate (TSP) and $\mathrm{PM}_{10}$ concentrations are the most direct parameters to assess this annoyance and to verify compliance with legal requirements defined in air quality standards.

Moreover, the assessment of $\mathrm{PM}_{10}$ concentration can be aimed to several purposes: long term investigations to establish quality standards, short term surveys to define spatial and temporal variation of airborne dust (e.g. Ukpebor et al. [6]), but also to locate point source, or to evaluate and test engineering controls. Furthermore the respirable fraction of airborne dust is useful in evaluating exposure of workers involved in dusty activities (e.g. Alfaro Degan et al. [1]).

Sampling method selection is strictly connected with the scope of measurements and a gravimetric method is usually selected to long term investigations while a photometric (light scattering) one is generally used in continuous surveys.

Gravimetric samplers collect air into the instrument at a specified flow rate under the action of a sampling pump. The air flow is collected on a $37 \mathrm{~mm}$ diameter PVC filter. The filter is weighed before and after the sampling period and mass concentration is finally assessed.

The light scattering aerosol monitors operate by illuminating aerosol passing through a defined volume and detecting the total light scattered by all the particles. In particular a modulated beam of infra red light is projected forward into a measurement chamber. The nephelometer has an internal pump drawing samples into the iso-kinetic sampling inlet where they meet sheath air that guides samples past the particle sensor. The sensor is a photo detector that measures the scattered light and generates a current pulse proportional to the received light intensity. The amount of light scattered is a complex function of many parameters the most important of are particle size, shape and refractive index. So, through an accurate calibration, for spherical particles of known refractive index, particle size can be detected and concentration assessed.

If on one side, gravimetric method allows an off line analysis of collected dust also aimed to characterize chemical and physical composition of samples, on the other one optical scattering method allows real time measurements and a huge reduction of sampling time. 
The paper is finally aimed to compare, according with a field study and measurements realized in a grey basalt quarry near Rome, these two different sampling techniques. In particular, it is organized as follows: in the first part equipment and methods adopted to the scope are described, then results from field studies and measurements are presented and a comparative analysis is discussed. Then the final passage aimed to improve measurement accuracy is presented: it consists in an accurate calibration of laser photometer to the specific dust, using gravimetrical sampler. This integrated approach showed an improvement of measurement accuracy due to the introduction of physical properties of sampled dust such as particle size distribution, refraction index and density.

\section{Equipment, materials and methods}

\subsection{Site description and sampling areas}

The field study was developed in an opencast Dark-Grey Basalt quarry, nearby Rome. The quarry was created in the early years of the XX century, with the purpose of providing Basalt to Rome-Ostia railway line, and still continues its activities extracting materials for B1 line of Rome subway.

The quarry operates a single 8-h shift per day, 5 days a week. Basalt is drilled and blasted and the shot rock is loaded onto haul trucks by front-end loaders and transported to the primary and secondary crushing plants where it is crushed and sized. The material is then conveyed to the final crushing and screening plants for further processing and stockpiling.

As known, most of the cited quarrying activities is classified as dusty one: drilling, blasting, loading and hauling materials, crushing, screening and conveying quarry materials implies impact on air quality and pollutant emission.

Because of site characteristics four monitoring locations were selected to better characterize the whole quarry plant and to measure airborne respirable dust concentration. These four stations placed at different points of the quarry plant were selected near the drilling and blasting area, the primary crushing plant, the secondary crushing plant and the access road.

Two different airborne particulate samplers were co-located at the selected four monitoring sites and three different sampling campaigns were carried out in the dry months of May and June 2012.

\subsection{Equipment}

To the scope, two airborne dust samplers were supplied by the Department of Industrial and Mechanical Engineering of University Roma Tre.

The gravimetric sampler consisted in personal sampling pump (Mod SKC 224PCEX8) set with a $2.5 \mathrm{l} / \mathrm{min}$ flow rate and a $37 \mathrm{~mm}$ aluminium cyclone. A $5 \mu \mathrm{m}$ pore size PVC filter was equilibrated in a room for balance at $20^{\circ} \mathrm{C} \pm 1^{\circ} \mathrm{C}$ and $50 \% \pm 5 \% \mathrm{RH}$, and then weighed with analytical balance (Mod. Exacta serie ABT 120-5 DM) with $0.01 \mathrm{mg}$ sensitivity. Each gravimetric sample had a two 
hour duration in order to collect a significant dust mass on the filter, according with the selected flow rate.

The light scattering sampler consisted in a Nephelometer (Sensidyne), real time dust monitor, with a sensivity from 1 to $10000 \mu \mathrm{g} / \mathrm{m}^{3}$, a resolution of $1 \mu \mathrm{g}$ and tuned to detect particles in the dimensional range between 0.1 and $10 \mu \mathrm{m}$. As previously described the measure was realized according with the light scattering method and the sampler was factory calibrated by comparing the instrument response to the respirable fraction of the International Standard of Organization (ISO) 12103-1. A Arizona Test Dust, by the gravimetric method NIOSH 0600.

\subsection{Sampling procedure}

Both the samplers were co-located at each sampling point. The sampling duration was defined by estimating the amount of collected dust mass and finally it was set on a two hour period.

As for gravimetric technique, each filter was weighted in the same conditions using an analytical balance with a precision of $10 \mu \mathrm{g}$, including field blanks. So each post sampling filter weigh was recorded besides its corresponding tare weight. The concentration of respirable particulate was finally assessed according with Standard NIOSH 0600 as follows:

$$
C=\frac{\left(W_{2}-W_{1}\right)-\left(B_{2}-B_{1}\right)}{V}
$$

where:

$\mathrm{C}$ is expressed $\left[\mu \mathrm{g} / \mathrm{m}^{3}\right]$

$\mathrm{W}_{1}=$ tare weight of filter before sampling $[\mu \mathrm{g}]$

$\mathrm{W}_{2}=$ post sampling weight of filter $[\mu \mathrm{g}]$

$\mathrm{B}_{1}=$ mean tare weight of blank filters $[\mu \mathrm{g}]$

$\mathrm{B}_{2}=$ mean post sampling weight of blank filters $[\mu \mathrm{g}]$

$\mathrm{V}=$ Volume as sampled at the nominal flow rate. [1/min]

As for optical samples, the sampling mode was the continuous one for a two hour duration. The concentration displayed was the two hour weighted average concentration all over the sampling period. Both minimum and maximum concentrations over the period were recorded in order to check possible interferences.

In this case the airborne dust concentration value was determined as follows:

$$
C=R * C P M
$$

where:

$\mathrm{C}$ is expressed in $\left[\mu \mathrm{g} / \mathrm{m}^{3}\right]$

$\mathrm{CPM}=$ particle count per minute $[\mathrm{n} / \mathrm{min}]$

$\mathrm{R}$ is a conversion parameter, factory calibrated, that is a complex function of particle characteristics and it is introduced to assess dust concentration from particle count. 
Each sample was repeated three times at each location in different days. The total amount of data collected was 12 both for gravimetric samples than optical ones.

Each sample was collected at the height of 1.5 meter by a tripod during the regular course of working activities without any interruption.

\section{Results}

\subsection{Sampled values}

Table 1 summarizes results from gravimetric campaign. As for location codes they respectively correspond to:

A - Drilling area;

B - Primary crushing plant;

C - Secondary crushing plant;

D - Access road.

In the table, number of samples is referred to data used to evaluate the mean concentration value and its standard deviation.

Table 1: Gravimetric samples at each location.

\begin{tabular}{|c|c|c|c|c|c|c|}
\hline \multirow{2}{*}{$\begin{array}{l}\text { Location } \\
\text { (Code) }\end{array}$} & $\begin{array}{c}\mathrm{N}^{\circ} \text { of } \\
\text { samples }\end{array}$ & \multicolumn{3}{|c|}{ Samples $\left(\mu \mathrm{g} / \mathrm{m}^{3}\right)$} & \multirow{2}{*}{$\begin{array}{c}\text { Avg. Concentration } \\
\left(\mu \mathrm{g} / \mathrm{m}^{3}\right)\end{array}$} & $\begin{array}{c}\text { Standard } \\
\text { Deviation } \\
\left(\mu \mathrm{g} / \mathrm{m}^{3}\right)\end{array}$ \\
\cline { 3 - 5 } & & $\# 1$ & $\# 2$ & $\# 3$ & & 824 \\
\hline $\mathrm{A}$ & 3 & 4390 & 5890 & 6310 & 5530 & 407 \\
\hline $\mathrm{B}$ & 3 & 4790 & 4030 & 3850 & 4223 & 610 \\
\hline $\mathrm{C}$ & 3 & 5720 & 4230 & 4870 & 4940 & 667 \\
\hline $\mathrm{D}$ & 3 & 3670 & 3530 & 5010 & 4070 & \\
\hline
\end{tabular}

Table 2: $\quad$ Light scattering samples at each location.

\begin{tabular}{|c|c|c|c|c|c|c|}
\hline \multirow{2}{*}{$\begin{array}{l}\text { Location } \\
\text { (Code) }\end{array}$} & $\begin{array}{c}\mathrm{N}^{\circ} \text { of } \\
\text { samples }\end{array}$ & \multicolumn{3}{|c|}{ Samples $\left(\mu \mathrm{g} / \mathrm{m}^{3}\right)$} & \multirow{2}{*}{$\begin{array}{c}\text { Avg. Concentration } \\
\left(\mu \mathrm{g} / \mathrm{m}^{3}\right)\end{array}$} & $\begin{array}{c}\text { Standard } \\
\text { Deviation } \\
\left(\mu \mathrm{g} / \mathrm{m}^{3}\right)\end{array}$ \\
\cline { 3 - 5 } & & $\# 1$ & $\# 2$ & $\# 3$ & & 703 \\
\hline $\mathrm{A}$ & 3 & 5010 & 5960 & 6730 & 5900 & 182 \\
\hline $\mathrm{B}$ & 3 & 4460 & 4380 & 4800 & 4546 & 523 \\
\hline $\mathrm{C}$ & 3 & 6310 & 5730 & 5030 & 5690 & 1114 \\
\hline $\mathrm{D}$ & 3 & 4550 & 3250 & 5980 & 4593 & \\
\hline
\end{tabular}

\subsection{Data comparison}

In order to test the differences between the two sets of values and hence the two samplers, a correlation analysis is presented. A Pearson product-moment correlation coefficient (PPMCC) is evaluated to assess the correlation between gravimetric samples and optical ones. Moreover a linear regression is modeled according to the expression showed in the following figure 1 where results are presented. The scatterplot shows a discrete strength of linear correlation $\left(\mathrm{R}^{2}=\right.$ 
0.7062), although a bias may be observed. Furthermore the coefficient of linear regression $(y=\beta x)$ with gravimetric values as independent variable and optical ones as dependant variable was 0.911 .

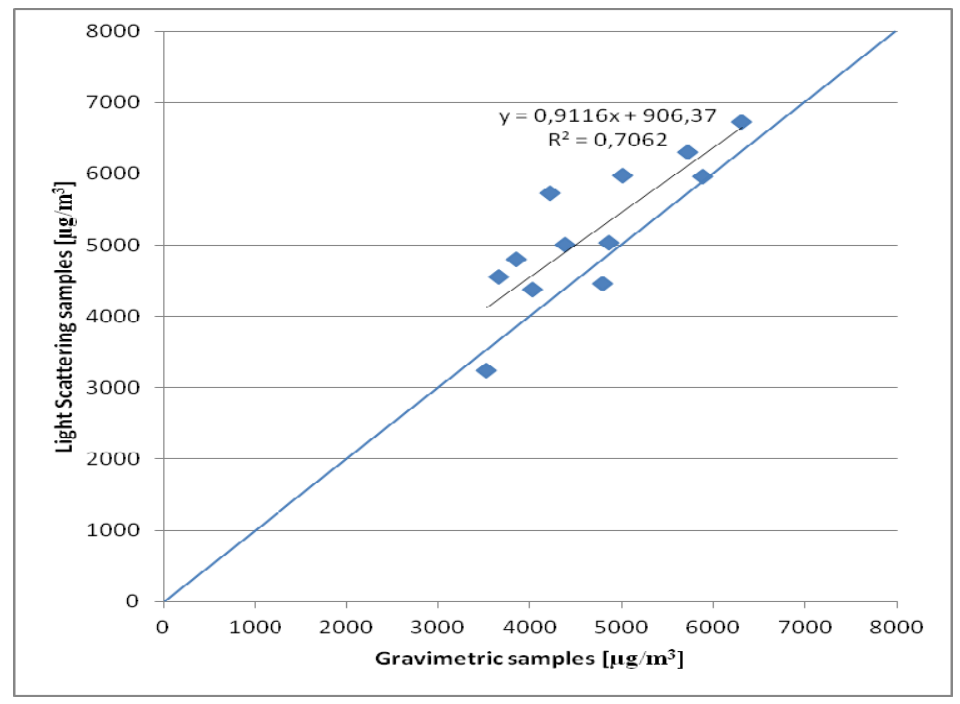

Figure 1: $\quad$ Scatterplot between gravimetric samples ( $\mathrm{X}$ axis) and optical ones (Y axis) both expressed in $\mu \mathrm{g} / \mathrm{m}^{3}$.

Moreover a further analysis aimed to define differences taking into account sampling location areas is summarized in the following table 3 .

Table 3: $\quad$ Gravimetric samples vs. optical data.

\begin{tabular}{|c|c|c|c|}
\hline $\begin{array}{c}\text { Location } \\
(\text { code })\end{array}$ & $\begin{array}{c}\text { Gravimetric samples } \\
\text { Avg conc. }\left(\mu \mathrm{g} / \mathrm{m}^{3}\right)\end{array}$ & $\begin{array}{c}\text { Optical samples } \\
\text { Avg conc. }\left(\mu \mathrm{g} / \mathrm{m}^{3}\right)\end{array}$ & $\begin{array}{c}\text { Difference } \\
\left(\mu \mathrm{g} / \mathrm{m}^{3}\right)\end{array}$ \\
\hline $\mathrm{A}$ & 5530 & 5900 & 370 \\
\hline $\mathrm{B}$ & 4223 & 4546 & 323 \\
\hline $\mathrm{C}$ & 4940 & 5690 & 750 \\
\hline $\mathrm{D}$ & 4070 & 4593 & 523 \\
\hline Mean value & 4690 & 5182 & 492 \\
\hline St. deviation & 870 & 944 & 74 \\
\hline
\end{tabular}

In order to reduce the bias and providing a more accurate reading of dust concentration levels from optical dust monitor, calibration procedure gravimetric/optical integrated was performed. In particular it was realized using simultaneous available samples at the same locations as follows.

First of all a $\mathrm{K}$ calibration factor was defined for each couple of samples using the following formula:

$$
K_{n}=\frac{D_{n}}{R_{n}}
$$

where: 
$\mathrm{K}_{\mathrm{n}}=$ calibration factor for the $\mathrm{n}$-th couple of samples.

$\mathrm{D}_{\mathrm{n}}=$ dust concentration from the $\mathrm{n}$-th gravimetric sample.

$\mathrm{R}_{\mathrm{n}}=$ dust concentration from $\mathrm{n}$-th light scattering sample.

Results are presented in table 4 where the sample code identifies the sample location and its progressive number.

Table 4: $\quad$ Calibration factors.

\begin{tabular}{|c|c|c|c|}
\hline Sample Code & K factor & Sample Code & K factor \\
\hline $\mathrm{A}_{1}$ & 0,90 & $\mathrm{C}_{1}$ & 0,87 \\
\hline $\mathrm{A}_{2}$ & 0,73 & $\mathrm{C}_{2}$ & 0,98 \\
\hline $\mathrm{A}_{3}$ & 0,96 & $\mathrm{C}_{3}$ & 0,93 \\
\hline $\mathrm{B}_{1}$ & 1,07 & $\mathrm{D}_{1}$ & 0,80 \\
\hline $\mathrm{B}_{2}$ & 0,92 & $\mathrm{D}_{2}$ & 1,08 \\
\hline $\mathrm{B}_{3}$ & 0,80 & $\mathrm{D}_{3}$ & 0,83 \\
\hline
\end{tabular}

Then the mean value of K (0.91) was assessed and finally assigned to the light scattering device to better fit particle characteristics of surveyed aerosol. The final step consisted in a field validation of the applied procedure to test the reliability of the calibration procedure.

The final measurement campaign was carried out in the dry month of July 2012.

It consisted in five samples collected at each of the four locations previously selected (A, B, C, D) with an additional value sampled at the truck loading area. The sampled values are presented in tables 5 and 6 .

Table 5: $\quad$ Post calibration samples.

\begin{tabular}{|c|c|c|}
\hline Location code & Gravimetric samples $\left(\mu \mathrm{g} / \mathrm{m}^{3}\right)$ & Optical samples $\left(\mu \mathrm{g} / \mathrm{m}^{3}\right)$ \\
\hline A & 3910 & 4310 \\
\hline B & 4360 & 4660 \\
\hline C & 5280 & 5680 \\
\hline D & 4380 & 4150 \\
\hline E & 4190 & 4570 \\
\hline
\end{tabular}

Table 6: $\quad$ Post calibration cumulative data.

\begin{tabular}{|l|c|c|}
\hline & Gravimetric samples $\left(\mu \mathrm{g} / \mathrm{m}^{3}\right)$ & Optical samples $\left(\mu \mathrm{g} / \mathrm{m}^{3}\right)$ \\
\hline $\mathrm{N}^{\circ}$ of samples & 5 & 5 \\
\hline Avg Concentration & 4424 & 4714 \\
\hline St. deviation & 459,9 & 539,7 \\
\hline
\end{tabular}

The post calibration scatterplot is then developed and presented together with PPMCC in the following figure 2. An increasing of correlation factor is appreciated $\left(\mathrm{R}^{2}=0.79\right)$, together with a reduction of the bias. Moreover the coefficient of linear regression $(y=\beta x)$ was 1.036 . 


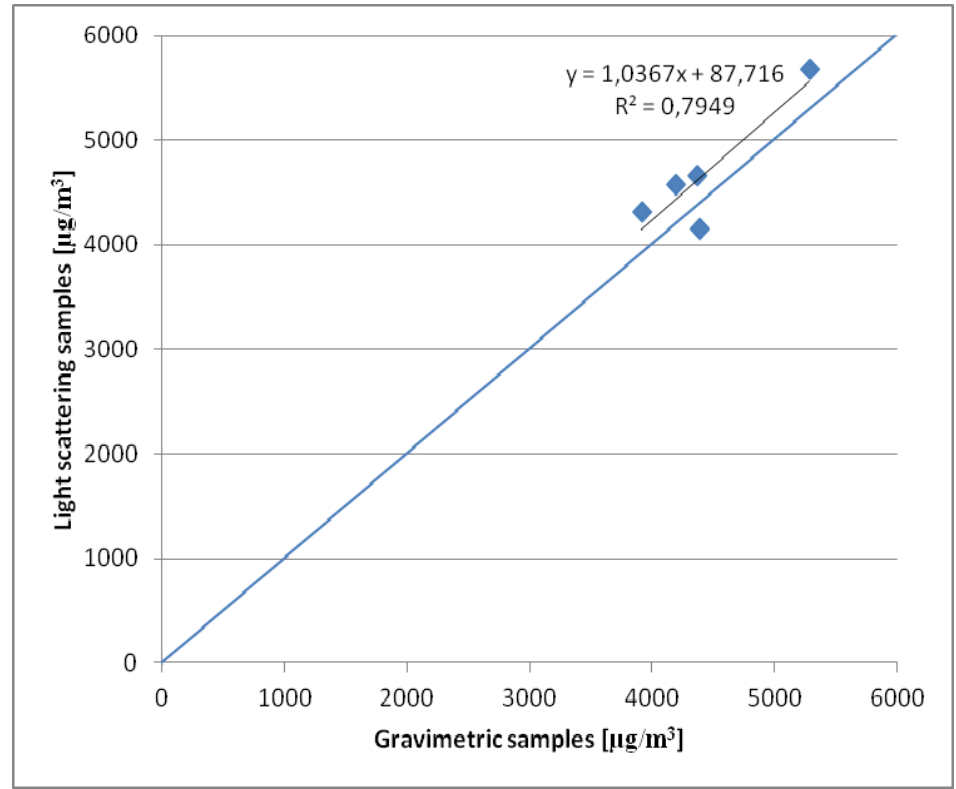

Figure 2: $\quad$ Post calibration data comparison.

\section{Discussion}

The comparison between the two sets of sampled values suggests some considerations the first of which is that the laser light scattering device overestimates airborne dust concentration from gravimetric sampler in each of the sampling campaigns.

In particular the mean value of optical device readings is higher than gravimetric ones by a $10-15 \%$ factor. This difference may be appreciated both in the first campaign and in the second one when a more accurate calibration is developed. This feature seems to point out the independence of such an over estimation from device calibration and requires further explanation. The inlet efficiency of real time detector may be one of the causes of this phenomenon together with its sensitivity.

The optical device has a sampling pump that draws aerosol into an inlet, through a length of duct, to the detector. Furthermore, as described, the device is factory calibrated by comparing the time weighed average photometer readings with gravimetric samples in a well defined aerosol but no pre classifier is installed (i.e. impactor or cyclone) to make response more similar to dust definitions (respirable fraction in this case). So the inlet efficiency can vary depending on air turbulence, orientation of sampling inlet and ratio of ambient air velocity to sampling air velocity. This last feature may be taken into account when sample is carried out in opencast quarries. At this purpose a future development of the present study may be represented by the collection of 
meteorological data referred to wind speed and direction in order to define correlation between air inlet efficiency and local air velocity.

Moreover the influence of rain, temperature and relative humidity should be estimated in order to study their correlation with airborne concentration.

The second contribution to optical device over estimation may be connected with its sensitivity. In particular, the nephelometer detects particles by measuring the amount of light they scatter. In this process the intensity of light scattered depends above all on particle size and also particle shape and refractive index and colour. As discussed by many authors (e.g. Thorpe and Walsh [5]), scattered light intensity is higher for smaller particles in the size range of 0.1 to $10 \mu \mathrm{m}$. This characteristic implies that without a preliminary size selection the signal from small particles dominates determining bias in the measure. Although the use of a narrow forward scattering angle reduces this effect, airborne particle size of quarry dust may fit these characteristics. In particular it is important to note that the higher difference between the two sets of data is observed at location $\mathrm{C}$, in the area of final crushing plant where material is small sized and airborne particle size is smaller.

To the scope a comparison between A1 Arizona road dust test and particle size characteristics of basalt quarry dust may represent a further step toward the best device calibration.

In conclusion the findings observed in this case study don't suggest that optical devices should substitute gravimetric samplers, but, although further analysis are to be developed, they provide a simple, fast and useful tool in assessing airborne dust concentration if integrated with a gravimetric method in the phase of calibration.

\section{References}

[1] Alfaro Degan G., Lippiello D., Pinzari M. and Alfaro Degan. Geostatistics and airborne dust: an Italian limestone quarry. Proc. of the $15^{\text {th }}$ International symposium on Mine planning and equipment selection, eds. Cardu M., Ciccu R., Lovera E., Michelotti E., Fiordo: Torino, pp. 923-928, 2006.

[2] ISO 12103-1. Test dust for filter evaluation. Part 1: Arizona Test Dust. Geneva, Switzerland: International Organization for Standardization (ISO). 1997.

[3] Lehocky H. and Williams PL, Comparison of respirable samplers to direct reading real time aerosol monitors for measuring coal dust. American Industrial Hygiene Association Journal, 57, pp. 557-563, 1996.

[4] Mahmoud Abdu Alaban et al. Road dust re suspension in the vicinity of Limestone quarries in Jordan. Journal of the Air and Waste Management association 56, pp. 1440-1444.

[5] Thorpe A. and Walsh PT. Performance testing of three portable, directreading dust monitors. Annals Occupational Hygiene Journal, 46. pp. 197207, 2001.

[6] Ukpebor E.E., Ukpebor J.E., Oviasogie P.O., Odiase J.I. and. Egbeme M.A, Field comparison of two Total Suspended Particulates (TSP) samplers to 
assess spatial variation. International Journal of Environmental Studies, 63 (5), pp. 567-577, 2006.

[7] Vella A.J. and Camilleri R. Fine dust emission from softstone quarrying in Malta. Xjenza 10, pp. 47-54, 2005.

[8] Yanosky J.D., Williams P.L. and MacIntosh D.L., A comparison of two direct reading aerosol monitors with the federal reference method for $\mathrm{PM}_{2.5}$ in indoor air, Atmospheric Environment 36, pp. 107-113. 